\title{
Livestock-Product Nitrogen-Footprint: a Fresh Method to Assess the Sustainability of Livestock Breeding
}

\author{
Saijun ZHOU 1,a, Mingjun DENG ${ }^{2}$ and Wenbing LUO² \\ 1 School of Civil Engineering, Hunan University of Science and Technology, Xiangtan 411201, China; \\ ${ }^{2}$ Business School of Hunan University of Science and Technology, Xiangtan 411201, China
}

Key words: Nitrogen footprint; livestock-product nitrogen footprint; sustainable development; assessment; livestock breeding

\begin{abstract}
Nitrogen-footprint is a new method developed in recent years to measure the impact of reactive nitrogen produced by human activities on the environment. Livestock-product nitrogen-footprint, which is based on life cycle assessment theory (LCA) and nitrogen footprint, is used to define and measure the nitrogen emissions during various stages of livestock production process, and it aims to offer guidance for livestock producers to adopt rationale livestock breeding methods to reduce nitrogen footprint and further to promote the sustainable development of livestock industry. With different research scopes, livestock-product nitrogenfootprint can be used to measure the sustainable development of livestock industry from the following four dimensions: 1) to measure the ecological features of the livestock products; 2) to measure the ecological features of livestock breeding enterprises; 3 ) to measure the nitrogen footprint of the livestock breeding zone, 4) to exert the function of environmental protection education for consumers. It will shed some light on the further study of livestock nitrogen footprint.
\end{abstract}

\section{Introduction}

Food systems--in particular, livestock production--are key drivers of environmental change ${ }^{[1]}$. According to Mark Sutton of the UK's Centre for Ecology and Hydrology, the amount of livestock we choose to have and the amount of animal protein we choose to eat are two critical factors in determining the scale of nitrogen pollution ${ }^{[2]}$. The main reason is that the livestock emits a large amount of $\mathrm{N}_{2} \mathrm{O}$, whose greenhouse effect is $296 \sim 310$ times that of $\mathrm{CO}_{2}{ }^{[3]}$. As the world's largest livestock-breeding country, China's production and consumption of animal products ranked among the top of the world. At the end of Year 2010, China's stock of pigs, cattle, poultry reached about 460 million, 110 million, and 535 million respectively, and ammonia emissions from livestock industry accounted for $25 \%$ of the national total emissions, 2.3 times the emissions from industrial sources of the year ${ }^{[4]}$. Large-scale livestock breeding generates about 3 billion tons of waste annually. These waste emissions together with nitrogen emission from the growing of crops required for livestock feeding and energy consumption have become one of the main sources of nitrogen pollution. Therefore, it is essential for the livestock industry to develop sustainably with the environment by reducing nitrogen emissions to reduce nitrogen footprint of livestock products. Studies have pointed out: to reduce and prevent the breeding pollution, and to restrict livestock stocking are the two ways to

a Corresponding author : zsjaw0745@sina.com 
promote the sustainable development of livestock industry ${ }^{[5]}$, but the present studies did not quantify the emissions of nitrogen pollutants at various stages of livestock breeding. Hence it is quite important to establish a standard method to measure and reduce nitrogen emissions of the whole process of livestock breeding, so as to promote its sustainable development.

\section{Concepts: Sustainable Development of Livestock Breeding and Livestock-product Nitrogen Footprint}

\subsection{Sustainable Development of Livestock Breeding}

The concept of "sustainable development" first appeared in the guideline document "World Conservation Strategy" in 1980, and in 1987 it was defined by Brundtland Report ---"Our Common Future" submitted by United Nations World Commission on Environment and Development. Sustainable development is a process for meeting human development goals while maintaining the ability of natural systems to continue to provide the natural resources and ecosystem services upon which the economy and society depend ${ }^{[6]}$. This definition was warmly received at the United Nations conference on environment and development in 1992, and then became popularized around the world as a new kind of development model of human society. It can be applied to various areas such as tourism, industry and agriculture, etc. In light of this, sustainable development of livestock breeding just refers to that livestock breeding industry can not only meet the demand of social economic life, but also meet the needs of the development of environmental protection.

\subsection{Livestock-product Nitrogen Footprint}

\subsubsection{Concept and Model of Nitrogen Footprint}

Nitrogen footprint is the fourth footprint concept, following ecological footprint, carbon footprint and water footprint. It first appeared in the $\mathrm{N}$ - print website ${ }^{[7]}$, as a new indicator to measure the total amount of reactive nitrogen emission to the environment caused by human activity. Leach argues that a nitrogen footprint is the total amount of reactive nitrogen released to the environment as a result of an entity's activities ${ }^{[8]}$; Qin Shuping suggests that a nitrogen footprint is the total amount of reactive nitrogen released directly or indirectly by a product or service in the process of production, transportation, storage and consumption ${ }^{[9]}$.

Based on the concept of nitrogen footprint, Leach and her colleagues developed a nitrogen footprint calculator (N-Calculator) online to calculate the reactive nitrogen released by an individual ${ }^{[8]}$, mainly involving nitrogen footprint from food and energy. Built on the nitrogen input and output data of the common food varieties and the main energy goods in the process of production, transportation and consumption, the model calculates an individual's nitrogen footprint from such four aspects as food, housing, travel as well as goods and services, and finally gets his yearly nitrogen footprint. NCalculator quantifies and distinguishes different aspects of an individual's nitrogen footprint, allowing people to know their personal nitrogen emissions from different activities. It is helpful to guide the public to change their consumption structure, and reduce the individual nitrogen footprint. But NCalculator is based on the consumption end, it fails to clarify the nitrogen amount emitted at different stages of the production activities, so it cannot offer guidance for producers to reduce nitrogen footprint efficiently. Therefore, based on $\mathrm{N}$ - Calculator, this study puts forward the concept of livestock-product nitrogen-footprint, analyzes the nitrogen emissions produced by resource and energy consumption in the production process of livestock products so as to give a comprehensive evaluation of the production process of livestock products, aiming to provide a reference for making policies and measures reducing the impact of reactive nitrogen on environment. 


\subsubsection{Concept of Livestock-product Nitrogen Footprint}

The concept of livestock-product nitrogen-footprint will be defined in light of the concept and analysis method of nitrogen-footprint together with life cycle assessment (LCA). LCA is a theory of environmental accounting, derived from human needs to protect the environment and make sustainable development. It is a tool used to assess the environmental impacts from a product (or a service) over the entire life cycle (from raw material extraction to processing, transportation, marketing, use, maintenance, recycling, and waste) ${ }^{[10]}$. So livestock-product nitrogen-footprint can refer to all the emission of reactive nitrogen from livestock-product related resource consumption and waste, i.e. the direct or indirect emission of reactive nitrogen from the whole process of "cradle to grave" (cultivation, processing, packing, transportation, refrigeration, cooking, and disposal).

\section{Calculating Method of Livestock-product Nitrogen Footprint}

Adopting the theory of LCA, which is bottom-up and process-based, and the evaluation method B2C (business-to-consumer) in PAS2050 [11], we can calculate the nitrogen footprint released during the life cycle via making an inventory of input and output of the entire life cycle in livestock breeding. The calculation process is as follows: establishing a list, boundary demarcation, data collection and nitrogen footprint calculation. Livestock product production is divided into several stages according to the list of life cycle: seedling production, breeding, processing, packaging, marketing and consumption. The system boundary of activities related to nitrogen emission of livestock production is as shown in Figure 1:

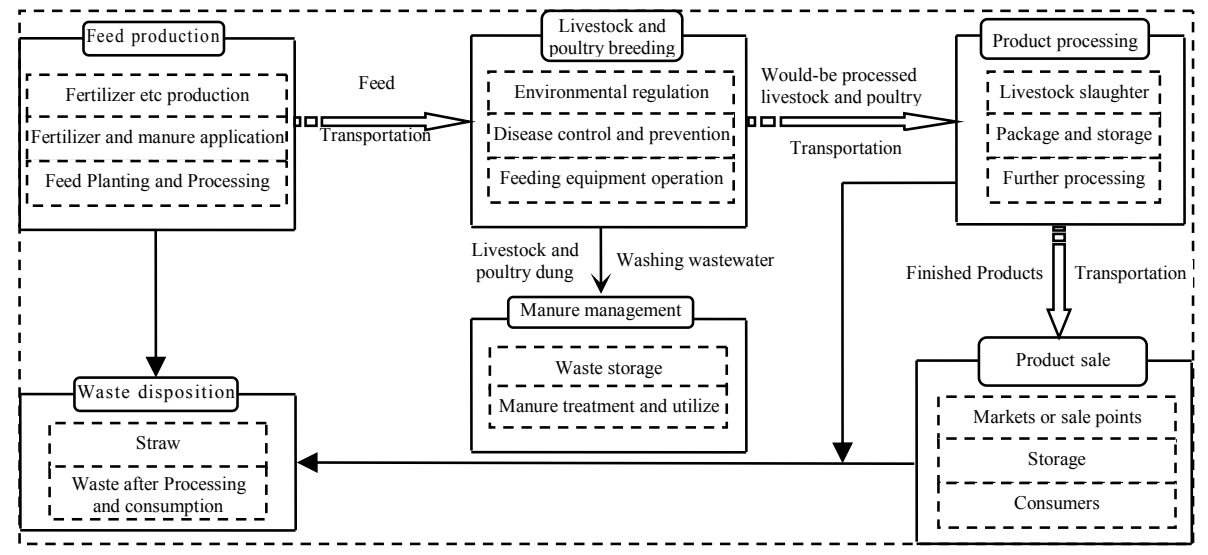

Figure 1. The assessment board line of livestock-product nitrogen footprint

With the inventory analysis and system boundary, the livestock-product nitrogen-footprint can be got with the following steps: collecting the data of energy and material consumption during different breeding stages, determining the associated emission factors, and calculating the nitrogen emission at various stages.

\section{Functions of Livestock-product Nitrogen-Footprint on the Sustainable Development of Livestock Breeding}

The function of livestock-product nitrogen-footprint is to establish a method to evaluate the sustainable way of livestock breeding and livestock consumption. This method can measure the impact of livestock breeding and consumption activities on the environment more scientifically, so it can fully and truly evaluate the livestock breeding industry to help achieve its sustainable development. According to different research scope, it can exert its measure functions on livestock 
product, livestock breeding industry, macro-scale livestock breeding base, livestock products businesses and consumers, etc.

\subsection{To Measure Livestock Products}

Livestock-product nitrogen-footprint can be used to measure the ecological features of the livestock products. The nitrogen footprint of different food varies widely. For example, the nitrogen footprint of meat and dairy foods is far higher than that of grains and carbohydrates ${ }^{[12]}$; the nitrogen footprint of livestock products is much higher than that of vegetables: beef has the highest nitrogen footprint value of about $500 \mathrm{~g} / \mathrm{kg}$, while sugar beet, fruit, vegetables and potatoes have the lowest nitrogen footprint of about $2 \mathrm{~g} / \mathrm{kg}^{[13]}$. The nitrogen footprint of different livestock products also varies widely. Chatzimpiros and Barles' research shows: nitrogen footprint of beef, pork and milk in France is $11.1 \mathrm{~kg} \mathrm{~N} . \mathrm{cap}^{-1} \cdot \mathrm{a}^{-1}$, $7.5 \mathrm{~kg} \mathrm{~N}$. $\operatorname{cap}^{-1} \cdot \mathrm{a}^{-1}$ and $2.3 \mathrm{~kg} \mathrm{~N}$. $\operatorname{cap}^{-1} \cdot \mathrm{a}^{-1}$ respectively ${ }^{[14]}$. Gertz's studies shows: the production of a pound of dairy food can release 1.1 ounces nitrogen pollution, second only to beef ${ }^{[15]}$. So, the calculation of the nitrogen footprint of different livestock products offers a chance to compare the impact of natural resource consumption by different livestock products on environment so as to judge whether the product is environment-friendly and whether the breeding can be developed sustainably.

\subsection{To Measure Livestock Breeding Enterprises}

The calculation of livestock-product nitrogen-footprint involves the whole production process of livestock products. We can demarcate the boundary between different phases in the process of producing livestock products to obtain the nitrogen input and output data of the life cycle, and then calculate the total nitrogen footprint of the products. For example, Leach calculates the flow of nitrogen of beef in the entire production process in U.S. ${ }^{[8]}$. Similarly, the nitrogen footprints of other kinds of livestock products can be calculated. In this way, the nitrogen footprint of the whole livestock breeding enterprise can be obtained. Measuring nitrogen emission of various products throughout its life cycle is beneficial for the breeding enterprise to identify and save cost, and the enterprise can take the nitrogen emission in the following stages into consideration: seedling provision, feed supply, breeding, slaughtering and processing, and make efforts to reduce nitrogen emissions. The comparison between nitrogen footprint of livestock breeding enterprise and the industry emission standards "Discharge standard of pollutants for livestock and poultry breeding" can be used to evaluate whether the livestock breeding enterprise is ecological and whether it has the potential of sustainable development.

\subsection{To Measure Livestock Breeding Zone}

Livestock product nitrogen footprint can reflect the impact of the resources and energy consumed by livestock and poultry breeding on the environment in the breeding zone. Livestock breeding consumes a lot of feed and water, and livestock products need slaughtering, processing and transport, producing a large amount of waste. All these resources and energy consumptions are of huge impact on the environment. Calculation of livestock-product nitrogen footprint can distinguish nitrogen emissions of different stages, truly reflecting the impact of nitrogen emissions of different stages on the local environment. It can also reflect the extent of dependency of the breeding zone on the other areas. Each region's ecological environmental bearing capacity is limited, and feed, energy and other supplies needed for livestock breeding are sometimes not produced in the local areas, but traded from other areas. By way of trade, nitrogen footprint of the livestock breeding area is transferred to other areas. The transferred nitrogen footprint reflects the extent of its dependency on the other areas. 


\subsection{The Function of Environmental Protection Education for Consumers}

The concept and calculation method of livestock product nitrogen footprint are easy to understand. The nitrogen label ${ }^{[16]}$ put directly on the package of livestock products informs consumers of the product nitrogen footprint, which makes it easy to for consumers to know and accept. Consumers are the important participants in the sustainable development; their way of life and consumption habits will directly affect the sustainable development of livestock breeding industry. EU Nitrogen pollution survey report points out that $85 \%$ of organic nitrogen in the Europe-produced or imported food is consumed by livestock. It seems that the nitrogen consumption is directly linked to meat, and it has become an important indicator to measure one's living standard. The concept of livestock product nitrogen footprint, therefore, can be effectively used to disseminate knowledge on environmental and ecological protection to consumers, and make them form a healthy habit of livestock product consumption to reduce nitrogen footprint, and contribute to the sustainable development of livestock breeding industry.

\section{Acknowledgments}

This research work was financially supported by MOE (Ministry of Education in China) Project of Humanities and Social Science(No. 13YJCZH276 and No. 14YJA630039).

\section{References}

[1] N. Pelletier, P. Tyedmers Forecasting. potential global environmental costs of livestock production 2000-2050. PNAS .Vol.107-43(2010), p.18371

[2] Nitrogen footprint warning from European agency. http://www.theguardian.com/environment/2011/apr/10/ nitrogen-footprint-europe-warning. Accessed 07 Jan. 2015.

[3] IPCC. Climate Change 2007: The Physical Science Basis[R]. Cambridge: Cambridge University Press,2007.

[4] The Environmental Protection Department of the People's Republic of China. The national livestock and poultry breeding pollution prevention and control of the 12th five-year plan.[EB/OL]. http://www.ygsite.cn/show.asp?id=53923

[5] X. Wang. Study on Sustainable Development of Regional Livestock and Poultry Breeding Industry. Chongqing: Chongqing University, 2008.

[6] C.X. Liu, J.C. Cheng, Q. Li. Basic theoretical analysis of sustainable development. China Population, Resources and Environment. Vol.9-2 (1996), p.3

[7] http://www.n-print.org. Accessed 20 May 2014.

[8] A.M. Leach, J.N. Galloway, A. Bleeker, et al. A nitrogen footprint model to help consumers understand their role in nitrogen losses to the environment. Environ Dev. Vol. 1-1 (2012), p.40

[9] S.P. Qin, C.S. Hu, Y.M. Zhang. Advance in nitrogen footprint research. Chinese Journal of Eco-Agriculture. Vol. 19-2 (2011), p.462

[10] International Organization for Standardization. ISO 14044 : 2006 . [EB/OL]. $\mathrm{http} / / /$ www.iso.org/iso/iso_catalogue/ catalogue_tc/catalogue_detail.htm?csnumber=29872, 2006-06-30

[11] PAS 2050: 2008-Specification for the assessment of the life cycle greenhouse gas emissions of goods and services.

[12] X. Xue, A.E. Landis. Eutrophication potential of food consumption patterns. Environ. Sci. Technol. Vol. 4416 (2010), p.6450

[13] A. Leip, F. Weiss, J.P. Lesschen and H. Westhoek. The nitrogen footprint of food products in the European Union. J Agr. Sci. 2013,p.1. DOI: 10.1017/S0021859613000786.

[14] P. Chatzimpiros, S. Barles. Nitrogen food-print: N use related to meat and dairy consumption in France. Biosci. Vol. 10(2013), p.71

[15] http://www.organicconsumers.org/articles/article_21368.cfm. Accessed 20 May 2014.

[16] J.N. Galloway, W. Winiwarter. Nitrogen footprints: past, present and future. Environ. Res. Lett. Vol.9(2014), p. 9 